\title{
Thermodynamic Functions for Molecular Oxygen in the Ideal Gas State
}

\author{
By Harold W. Woolley
}

\begin{abstract}
The thermodynamic functions for molecular oxygen in the ideal gas state have been calculated using recent values of physical and spectroscopic constants. Values of $C_{p}{ }^{\circ}, H^{\circ}-E_{0}^{\circ}$, $-\left(\mathrm{F}^{\circ}-\mathrm{E}_{0}^{\circ}\right) / T$, and $S^{\circ}$ are given, directly calculated or interpolated, for every twenty degrees up to $700^{\circ} \mathrm{K}$ and for every hundred degrees up to $5,000^{\circ} \mathrm{K}$.
\end{abstract}

\section{Introduction}

A table of thermodynamic functions for molecular oxygen based on the latest spectroscopic data and values of physical constants was desired. Simple adjustment of the values published by Johnston and Walker $[1,2]^{1}$ seemed inadequate because of the complexity of the changes to be made in the spectroscopic constants. The new table is based entirely on newly computed values.

\section{Spectroscopic Constants}

The spectroscopic data used by Johnston and Walker have been revised to conform to the results of Curry and Herzberg [3] and Schlapp [4] for the ground state. For the ${ }^{1} \Delta_{g}$ state, the constants used are based on the recent values of Herzberg and Herzberg [5]. Constants for the ${ }^{1} \Sigma_{o}^{+}$state and the ${ }^{3} \Sigma_{u}^{-}$state have been taken from the tables of Sponer [6]. For the ${ }^{3} \Sigma_{u}^{+}$state, approximate values of spectroseopic constants were selected, using a tentative identification of the Herzberg bands [7] proposed by Swings [8]. Several minor spectroscopic constants have been obtained with Dunham's formulas [9]. The improved theory of the ground state given by Schlapp introduces a slight shift in the calculated value of the unobserved lowest level. As this is the level to which all other levels are referred for purposes of thermochemical calculations, numerical values are altered slightly for all electronic states.

1 Figures in brackets indicate the literature references at the end of this paper.
For states of diatomic molecules for which no splitting occurs due to spin or orbital interaction, the sum of electronic, vibrational, rotational, and vibrational-rotational interaction energies may be represented in wave numbers by the power series

$$
W=\sum_{j, k} Y_{j k}\left(v+\frac{1}{2}\right)^{j} K^{k}(K+1)^{k},
$$

using the notation of Dunham. Each electronic state has its own set of $Y_{j k}$ 's. The electronic energy can be considered as represented by $Y_{00}$, the vibrational by

$$
\sum_{j=1} Y_{j 0}\left(v+\frac{1}{2}\right)^{j}
$$

and the sum of rotational and rotational-vibrational interaction energy by

$$
\sum_{,=0, k=1} Y_{j k}\left(v+\frac{1}{2}\right)^{j} K^{k}(K+1)^{k} .
$$

The vibrational quantum number, $v$, can assume any integral value, and the rotational quantum number, $K$, can assume various integral values. For a homonuclear molecule, such as $\mathrm{O}_{2}^{16}$, there are half as many rotational states as for a comparable heteronuclear molecule. The ground state of $\mathrm{O}_{2}^{16}$ is a ${ }^{3} \Sigma_{\sigma}^{-}$state with odd values of $K$. For the ground state, spin interactions are important, and triplet splitting occurs with the $F_{1}$ and $F_{3}$ components, averaging about $2 \mathrm{~cm}^{-1}$ lower than the $F_{2}$ component. The results of an adequate theoretical treatment of the splitting have been given by Schlapp, including inter- 
actions neglected in the original treatment of Kramers [10]. The term values of the $F_{1}, F_{2}$, and $F_{3}$ components with $J=K+1, K$, and $K-1$, respectively, are given by the formulas

$$
\begin{gathered}
W_{K+1}=W_{0}+(2 K+3) B-\lambda- \\
{\left[(2 K+3)^{2} B^{2}+\lambda^{2}-2 \lambda B\right]^{\frac{1}{2}}+\mu(K+1),} \\
W_{K}=W_{0}, \\
W_{K-1}=W_{0}-(2 K-1) B-\lambda+ \\
{\left[(2 K-1)^{2} B^{2}+\lambda^{2}-2 \lambda B\right]^{\frac{1}{2}}-\mu K,}
\end{gathered}
$$

with $B=1.438 \mathrm{~cm}^{-1}, \quad \lambda=1.985 \mathrm{~cm}^{-1}$, and $\mu=-0.008 \mathrm{~cm}^{-1}$. $W_{0}$ is given by eq 1 with constants listed below for the ${ }^{3} \Sigma_{0}^{-}$state. In accord with these equations, the lowest state is the $F_{3}$ level for $K=1$ and is $3.96 \mathrm{~cm}^{-1}$ below the corresponding $F_{2}$ level, or $1.09 \mathrm{~cm}^{-1}$ below the nonexistent $K=0$ level.

For the ${ }^{1} \Delta_{g}$ state, a double weighting due to $\Lambda$ doubling provides single levels for both odd and even values of $K$, with levels beginning at $K=1$, the value of $\Lambda$. For the ${ }^{1} \Sigma_{o}^{+}$state, $K$ has even values.

The states and spectroscopic constants used for $\mathrm{O}_{2}^{16}$ are

$$
{ }^{3} \Sigma_{o}^{-} \text {(ground state) }
$$

$$
\begin{aligned}
& Y_{00}=-786.08 \mathrm{~cm}^{-1} \\
& Y_{10}=1580.36 \mathrm{~cm}^{-1} \\
& Y_{20}=-12.073 \mathrm{~cm}^{-1} \\
& Y_{30}=0.0546 \mathrm{~cm}^{-1} \\
& Y_{40}=-0.00143 \mathrm{~cm}^{-1}
\end{aligned}
$$

$$
\begin{aligned}
& Y_{01}=1.4456 \mathrm{~cm}^{-1} \\
& Y_{11}=-0.0158 \mathrm{~cm}^{-1} \\
& Y_{02}=-4.838 \times 10^{-6} \mathrm{~cm}^{-1} \\
& Y_{12}=-4.96 \times 10^{-9} \mathrm{~cm}^{-1} \\
& Y_{03}=0.1387 \times 10^{-12} \mathrm{~cm}^{-1} \\
& Y_{04}=-32.2 \times 10^{-18} \mathrm{~cm}^{-1}
\end{aligned}
$$

$Y_{00}=7132.1 \mathrm{~cm}^{-1}$

$Y_{10}=1509.3 \mathrm{~cm}^{-1}$

$Y_{20}=-12.9 \mathrm{~cm}^{-1}$

$Y_{00}=12409.2 \mathrm{~cm}^{-1}$

$Y_{10}=1432.615 \mathrm{~cm}^{-1}$

$Y_{20}=-13.925 \mathrm{~cm}^{-1}$

$$
\begin{aligned}
& Y_{00}=35,385 \\
& Y_{10}=791.5 \\
& Y_{20}=-20.83 \\
& Y_{30}=0.83
\end{aligned}
$$

$Y_{00}=49,007$

$Y_{10}=709.57$

$Y_{20}=-10.708$
Corresponding spectroscopic constants were obtained for lower states of the heteronuclear $\mathrm{O}^{16}-\mathrm{O}^{17}$ and $\mathrm{O}^{16}-\mathrm{O}^{18}$ molecules, for which both odd and even rotational levels are present in each state.

\section{Method of Calculation}

The thermodynamic functions for the ideal gas state at atmospheric pressure are obtained from the partition function $Q$ by evaluating the formulas

$$
\begin{gathered}
\frac{H^{\circ}-E_{0}^{\circ}}{R T}=\frac{T}{Q} \frac{d Q}{d T}+\frac{5}{2} \\
-\frac{\left(F^{\circ}-E_{0}^{\circ}\right)}{R T}=\ln Q+\frac{3}{2} \ln M+\frac{5}{2} \ln T-3.6644 \\
\frac{S^{\circ}}{R}=\frac{H^{\circ}-E_{0}^{\circ}}{R T}-\frac{F^{\circ}-E_{0}^{\circ}}{R T} \\
\frac{C_{p}^{\circ}}{R}=\frac{T^{2}}{Q} \frac{d^{2} Q}{d T^{2}}-\left[\frac{T}{Q} \frac{d Q}{d T}-1\right]^{2}+\frac{7}{2} .
\end{gathered}
$$

where $T$ is temperature in degrees $\mathrm{K} ; M$ is the molecular weight on the chemical scale, 31.9913 for $\mathrm{O}_{2}^{16}, 32.9955$ for $\mathrm{O}^{16}-\mathrm{O}^{17}$, and 33.9956 for $\mathrm{O}^{16}-\mathrm{O}^{18}$; and $Q$, the partition function, or state sum, is given by $p e^{-\epsilon / K T}$, where $p=2 J+1$ and $\epsilon=h c W$. The contributions of the different electronic states are included by evaluating $Q=Q_{1}+Q_{2}+Q_{3}+\ldots$. and its derivatives, where $Q_{1}$ is for the ${ }^{3} \Sigma_{0}^{-}$state, $Q_{2}$ for the ${ }^{1} \Delta_{g}$ state, $Q_{3}$ for the ${ }^{1} \Sigma_{0}^{+}$state, etc.

In evaluating the $Q$ 's, or values of $\sum(2 J+1) e^{-h c W / k T}$, the [rotational energy is separated from the rest of the energy $W$, and the sum over rotation levels is expressed in terms of an integral. In this way it is found that the functions $Q_{i}$ and their derivatives are given by the formulas

$$
\begin{gathered}
Q_{i}=g \sum f e^{-x} \\
T \frac{d Q_{i}}{d T}=g\left[\sum T f^{\prime} e^{-x}+\sum f x e^{-x}\right] \\
T^{2} \frac{d^{2} Q_{i}}{d T}=g\left[\sum T^{2} f^{\prime \prime} e^{-x}+2 \sum T f^{\prime} x e^{-x}\right. \\
\left.-2 \sum f x e^{-x}+\sum f x^{2} e^{-x}\right],
\end{gathered}
$$

where $x$ is $G_{v} h c / k T$, with $G_{v}$ representing the sum of electronic and purely vibrational energy in $\mathrm{cm}^{-1}$, and where the summation extends over all vibrational levels up to dissociation. $G_{v}$ is thus that part of the total energy that is completely 
independent of the rotational quantum number, and is given by

$$
\sum_{j=0} Y_{j 0}\left(v+\frac{1}{2}\right)^{j}
$$

or its equivalent expressed as a polynomial in $v$. $g$ is an average weight factor in addition to the factor $2 J+1$ typical for the rotational levels of a simple rotating vibrator. For each electronic state, the quantity $f$, and its temperature derivatives, $f^{\prime}$ and $f^{\prime \prime}$, are functions of $T$ and $v$ obtained from

$f=\frac{4}{315} \frac{c_{2}^{2} B_{v}{ }^{2}}{T^{2}}+\frac{1}{15} \frac{c_{2} B_{v}}{T}+\frac{1}{3}+\frac{T}{c_{2}} \frac{1}{B_{v}}+\frac{T^{2}}{c_{2}^{2}}\left(-\frac{2 D_{v}}{B_{v}^{3}}\right)+\frac{T^{3}}{c_{2}^{3}} \frac{12 D_{v}^{2}-6 B_{v} F_{v}}{B_{v}^{5}}+\frac{T^{4}}{c_{2}^{4}} \frac{120 B_{v} D_{v} F_{v}-24 B_{v}^{2} H_{v}-120 D_{v}^{3}}{B_{v}^{7}} \ldots$,

with $c_{2}=h c / k$, as in the derivation given in reference [11]. Convergence difficulties discussed in that paper for the hydrogens do not occur for such molecules as $\mathrm{O}_{2}$. The spectrosopic constants $B_{v}, D_{v}, F_{v}$, and $H_{v}$, are given by $\sum_{j=0} Y_{j k}(v+1 / 2)^{j}$, with $k$ taking the values $1,2,3$, and 4 , respectively.
In using the above expressions, the vibrational energy, $G_{v}$, is ordinarily to be evaluated with respect to the lowest level of the ground state. The partition function for the ground state, including the effect of triplet splitting, as detailed in eq. 2 , may be represented as

$$
\begin{aligned}
Q_{1}= & \sum_{v}\left\{f_{e}+\left[e^{-h c(2 \lambda+\mu-2 B) / k T}+2 e^{-h c(\lambda+5 \mu / 2-2 B) / k T}\right] \sum_{K=1,3}(2 K+1) e^{\frac{-h c W}{K T}}\right\} \\
= & \sum_{v}\left\{f_{e}+\left[\frac{1}{3} e^{-h c(2 \lambda+\mu-2 B) / k T}+\frac{2}{3} e^{-h c(\lambda+5 \mu / 2-2 B) / k T}\right] \frac{3}{2} f_{0}\right\} \\
= & \sum\left\{f_{e}+e^{-h c(4 \lambda / 3+2 \mu-2 B) / k T} \cdot 3 / 2 f_{0}\left[1+\frac{1}{9}\left(\frac{h c}{k T}\right)^{2}(\lambda-3 \mu / 2)^{2}-\frac{1}{81}\left(\frac{h c}{k T}\right)^{3}(\lambda-3 \mu / 2)^{3}+\ldots\right]\right\} \\
= & e^{-h c(4 \lambda / 3+2 \mu-2 B) / k T} \frac{3}{2} \sum\left\{\frac{2}{3} f_{e}\left[1+\frac{h c}{k T}(4 \lambda / 3+2 \mu-2 B)+\ldots\right]\right. \\
& \left.\quad+f_{0}\left[1+\frac{1}{9}\left(\frac{h c}{k T}\right)^{2}(\lambda-3 \mu / 2)^{2}-\frac{1}{81}\left(\frac{h c}{k T}\right)^{3}(\lambda-3 \mu / 2)^{3} \ldots\right]\right\}
\end{aligned}
$$

$f_{0}$ represents the partition function that would be obtained for the ground state if the triplet splitting were negligibly small, and energies were reckoned from $K=0 . \quad f_{e}$ is a small correction term to which the only significant contribution above very low temperatures comes from the $K=1$ levels:

$$
\begin{aligned}
f_{e}= & 5 e^{\frac{-h c}{k T}\left[5 B-\left(25 B^{2}+\lambda^{2}-2 \lambda B\right)^{1 / 2}+\lambda+3 \mu-2 B\right]} \\
& +1-6 e^{\frac{-h c}{K T}[\lambda+5 \mu / 2-2 B]}=\frac{1.963}{T}-\frac{1.48}{T^{2}}+\ldots
\end{aligned}
$$

Equation 9 shows that the effect of the triplet splitting is most readily included for ordinary and elevated temperatures by introducing a small additive correction $4 \lambda / 3+2 \mu-2 B$, or $-0.244 \mathrm{~cm}^{-1}$, in the vibrational energy formula for the ground state and introducing small correction terms in the formula for $f$ to take account of its trends toward lower temperatures.
Evaluation of the expressions as far as appears justified with the present data gives the following for the various states for $\mathrm{O}_{2}^{16}$.

$$
{ }^{3} \sum_{0}^{-} \text {state, } g=\frac{3}{2}
$$

$$
\begin{aligned}
G_{v}= & -0.244+1568.33 v-11.993 v^{2}+ \\
& 0.0517 v^{3}-0.00143 v^{4} \\
f= & -\frac{1.232}{T^{2}}+\frac{1.8902}{T}+\frac{1}{3}+ \\
& (0.483562+0.005311 v) T+\left(1.5746 \cdot 10^{-6}+\right. \\
& \left.0.0535 \cdot 10^{-6} v\right) T^{2}+14.89 \cdot 10^{-12} T^{3}+267 \cdot 10^{-18} T^{4} . \\
{ }^{1} \Delta_{g} \text { state }, g=1 & \\
G_{v}= & 7883.5+1496.4 v-12.9 v^{2} \\
f=\frac{1}{3}+(0.49033+0.00599 v) T+1.709 \cdot 10^{-6} T^{2} & (11) \\
& { }^{1} \sum_{o}^{+} \text {state, } g=\frac{1}{2}
\end{aligned}
$$




$$
\begin{aligned}
& G_{v}=13122+1418.69 v-13.925 v^{2} \\
& f=\frac{1}{3}+(0.49944+0.006837 v) T+1.921 \cdot 10^{-6} T^{2} \\
& { }^{3} \sum_{u}^{+} \text {state, } g=\frac{3}{2} \\
& G_{v}=35776+771.2 v-19.74 v^{2}+0.63 v^{3}-0.099 v^{4} \\
& f=\frac{1}{3}+0.632 T /(1-0.0545 v)+6 \times 10^{-6} T^{2} \\
& { }^{3} \sum_{u}^{-} \text {state, } g=\frac{3}{2} \\
& G_{v}=49359+698.86 v-10.708 v^{2} \\
& f=\frac{1}{3}+(0.855+0.0145 v) T
\end{aligned}
$$

The values used for $R$ and $h c / k$ were 1.98714 (defined) cal $\mathrm{deg}^{-1} \mathrm{~mole}^{-1}$ and $1.4384 \mathrm{deg} \mathrm{cm}$, respectively.

For all electronic states treated, each summation over rotational levels for a given vibrational level was broken off at the top of the predissociation region applying to the vibrational level, by using a suitable upper limit in the integration given in reference [11]. This complicating restriction, which requires special treatment, is significant only at the highest temperatures.

The contributions of the several electronic states to the partition function and its derivatives for $\mathrm{O}_{2}^{16}$ are listed in tables 1,2 , and 3 . These values may facilitate any future revision of thermodynamic functions for oxygen if new spectroscopic data make it desirable. It is thought that in general these sums and their derivatives have been carried to more digits than correspond to the accuracy of the spectroscopic data. This is particularly the case for the ${ }^{1} \Delta_{g}$ state for which the anharmonicity constant has not been determined experimentally. The values given in brackets are the additional contributions that would be obtained if the rotational sums were extended to infinite energy as has been customary instead of limiting them to the region of quantized levels. These additional contributions are given to more decimal places than were used for the entire sums because of possible theoretical interest in their magnitudes. The information necessary for a

\begin{tabular}{|c|c|c|c|c|c|c|}
\hline Temperature & $\begin{array}{l}{ }^{3 \boldsymbol{\Sigma}_{\mathbf{g}}^{-}} \\
\left(Q_{1}\right)\end{array}$ & $\begin{array}{l}{ }^{1} \Delta_{g} \\
\left(Q_{2}\right)\end{array}$ & $\begin{array}{l}{ }^{1} \boldsymbol{\Sigma}_{\boldsymbol{g}}^{+} \\
\left(Q_{3}\right)\end{array}$ & $\begin{array}{l}{ }^{3} \Sigma_{v}^{+} \\
\left(Q_{4}\right)\end{array}$ & $\begin{array}{l}3 \Sigma_{u}^{-} \\
\left(Q_{5}\right)\end{array}$ & $\begin{array}{c}\text { Total } \\
(Q)\end{array}$ \\
\hline${ }^{\circ} K$ & & & & & & \\
\hline $100 \ldots$ & 73. 344 & & & & & 73. 344 \\
\hline $200 \ldots$ & 145.931 & & & & & 145. 931 \\
\hline $300 \ldots \ldots$ & 218.705 & & & & & 218. 705 \\
\hline $400 \ldots$ & 292. 374 & & & & & 292. 374 \\
\hline $600 \ldots$ & 447. 681 & & & & & 447. 681 \\
\hline 800 & 620.90 & 0.00 & & & & 620.90 \\
\hline $1,000 \ldots$ & 816.90 & .01 & & & & 816.91 \\
\hline $1,250 \ldots$ & 1097. 27 & .09 & . & & & 1097. 36 \\
\hline $1,500 \ldots$ & 1418.91 & .51 & 0.00 & & & 1419.42 \\
\hline $1,750 \ldots$ & 1783.03 & 1.90 & .01 & & & 1784.94 \\
\hline 2,000 & 2190.46 & 5. 26 & .06 & & & 2195. 78 \\
\hline $2,500 \ldots$ & 3138.02 & 23.52 & .61 & & & 3162.15 \\
\hline $3,000 \ldots$ & 4266.61 & 68. 37. & 2. 96 & 0.00 & & 4337.94 \\
\hline $4,000 \ldots \ldots$ & $\begin{array}{r}7086.4 \\
{[.02]}\end{array}$ & $\begin{array}{c}293.7 \\
{[.01]}\end{array}$ & $\begin{array}{c}23.97 \\
{[.004]}\end{array}$ & $\begin{array}{c}.04 \\
{[.024]}\end{array}$ & 0.00 & 7404.1 \\
\hline 5,000 & $\begin{array}{r}10690.4 \\
{[.47]}\end{array}$ & $\begin{array}{c}784.8 \\
{[.24]}\end{array}$ & $\begin{array}{c}93.8 \\
{[.12]}\end{array}$ & $\begin{array}{c}.76 \\
{[.66]}\end{array}$ & .02 & 11569.8 \\
\hline
\end{tabular}
satisfactory calculation of the state sums for the vibrational states near the dissociation limit is not

\begin{tabular}{|c|c|c|c|c|c|c|}
\hline Temperature & $\begin{array}{c}3 \Sigma_{g}^{-} \\
\left(T Q_{1}^{\prime}\right)\end{array}$ & $\begin{array}{l}{ }^{1} \Delta_{8} \\
\left(T Q_{2}^{\prime}\right)\end{array}$ & $\begin{array}{c}1 \Sigma_{g}^{+} \\
\left(T Q_{3}^{\prime}\right)\end{array}$ & $\begin{array}{c}3 \Sigma_{u}^{+} \\
\left(T Q_{4}^{\prime}\right)\end{array}$ & $\begin{array}{c}{ }^{3} \Sigma_{u}^{-} \\
\left(T Q_{5}^{\prime}\right)\end{array}$ & $\begin{array}{l}\text { Total } \\
\left(T Q^{\prime}\right)\end{array}$ \\
\hline${ }^{\circ} K$ & & & & & & \\
\hline 100 & 72.551 & & & & & 72.551 \\
\hline $200 \ldots$ & $145: 272$ & 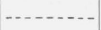 & & & & 145. 272 \\
\hline $300 \ldots$ & 219.098 & 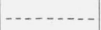 & & & & 219. 098 \\
\hline $400 \ldots$ & 298.152 & - & & & & 298. 152 \\
\hline $600 \ldots$ & 489.366 & 0.000 & & -- & & . 489.366 \\
\hline $800 \ldots$ & 736. 328 & .005 & & & & 736.333 \\
\hline $1,000 \ldots$ & 1041.33 & .08 & .. & & & 1041.41 \\
\hline $1,250 \ldots$ & 1503.77 & .91 & 0.00 & & & 1504.68 \\
\hline $1,500 \ldots$ & 2056. 30 & 4. 62 & .02 & & & 2060.94 \\
\hline 1,750 & 2699. 56 & 15. 22 & .17 & & & 2714.95 \\
\hline 2,000 & 3434.68 & 38.16 & .71 & & & 3473.55 \\
\hline 2,500 & 5186.33 & 146. 06 & 5.66 & & & 5338.05 \\
\hline $3,000 \ldots$ & $\begin{array}{r}7324.29 \\
{[.002]}\end{array}$ & $\begin{array}{r}377.28 \\
{[.001]}\end{array}$ & 23.81 & 0.0 & & 7725.38 \\
\hline 4,000 & $\begin{array}{r}12819.6 \\
{[.3]}\end{array}$ & $\begin{array}{r}1370.2 \\
{[.14]}\end{array}$ & $\begin{array}{r}157.6 \\
{[.07]}\end{array}$ & $\begin{array}{c}.6 \\
{[.4]}\end{array}$ & 0.0 & 14348.0 \\
\hline 5,000 & $\begin{array}{r}20050.9 \\
{[6.3]}\end{array}$ & $\begin{array}{r}3267.1 \\
\text { [3. 2] }\end{array}$ & $\begin{array}{l}534.2 \\
{[1.6]}\end{array}$ & $\begin{array}{c}8.8 \\
{[8.9]}\end{array}$ & .4 & 23861. 4 \\
\hline
\end{tabular}
available. An analysis of the problem has been started in connection with this paper and previous work [11] and may be completed in a future publication.
TABle 1. Values of $Q$ for $\mathrm{O}_{2}{ }^{16}$

TABLE 2. Values of $T d Q / d T$ for $\mathrm{O}_{2}^{16}$

The calculations which have been described were for $\mathrm{O}_{2}{ }^{16}$. Thermodynamic functions for ordinary oxygen may be obtained from those for $\mathrm{O}_{2}{ }^{16}$ by making small adjustments in the values. In the naturally occurring mixture of isotopic oxygen, 99.526 percent of the molecules are $\mathrm{O}_{2}{ }^{16}$, 0.394 percent are $\mathrm{O}^{16}-\mathrm{O}^{18}$, and 0.080 percent are $\mathrm{O}^{16}-\mathrm{O}^{17}$, according to the isotope data given by Birge [12]. The tables of Gordon and Barnes [13] were used in calculating the minute changes in the thermodynamic functions due to the 
presence of isotopic molecules and for some other calculations for which the tables were advantageous. The contribution to $S^{\circ}$ and to $-\left(F^{\circ}-E_{0}^{\circ}\right) / T$ due to the presence of both odd and even rotational levels in $\mathrm{O}^{16}-\mathrm{O}^{17}$ and $\mathrm{O}^{16}-\mathrm{O}^{18}$ amounts to

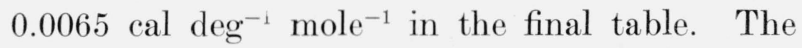
entropy of mixing of isotopes, amounting to $0.0677 \mathrm{cal} \mathrm{deg}^{-1} \mathrm{~mole}^{-1}$, was not included. Similarly, no entropy of nuclear spin has been included. The quantities that were added to the thermodynamic functions for $\mathrm{O}_{2}{ }^{16}$ to obtain values for the isotope mixture are given in table 4 .

Table 3. Values of $T^{2} d^{2} Q / d T^{2}$ for $\mathrm{O}_{2}^{16}$

\begin{tabular}{|c|c|c|c|c|c|c|}
\hline Temperature & $\begin{array}{c}{ }^{3} \Sigma_{o}^{-} \\
\left(T^{2} Q_{1}^{\prime \prime}\right)\end{array}$ & $\begin{array}{c}{ }^{1} \Delta_{0} \\
\left(T^{2} Q_{2}^{\prime \prime}\right)\end{array}$ & $\begin{array}{c}1 \Sigma_{o}^{+} \\
\left(T^{2} Q_{3}^{\prime \prime}\right)\end{array}$ & $\begin{array}{c}{ }^{3 \Sigma_{u}^{+}} \\
\left(T^{2} Q_{4}^{\prime \prime}\right)\end{array}$ & $\begin{array}{c}{ }^{3} \Sigma_{u}^{-} \\
\left(T^{2} Q_{5}^{\prime \prime}\right)\end{array}$ & $\begin{array}{l}\text { Total } \\
\left(T^{2} Q^{\prime \prime}\right)\end{array}$ \\
\hline${ }^{\circ} K$ & & & & & & \\
\hline $\begin{array}{l}100 \ldots \\
200\end{array}$ & $\begin{array}{r}0.108 \\
.466\end{array}$ & & & & & $\begin{array}{r}0.108 \\
.466\end{array}$ \\
\hline $300 \ldots$ & 7. 523 & & & & & 7. 523 \\
\hline $400 \ldots$ & 35. 539 & 0.000 & & & & 35. 539 \\
\hline $600 \ldots$ & 164. 969 & .001 & & & & 164. 970 \\
\hline 800 & 367.677 & .061 & & & & 367.738 \\
\hline $1,000 \ldots$ & 628.33 & .91 & 0.00 & & & 629. 24 \\
\hline 1,250 & 1033. 40 & 7.85 & .03 & & & 1041. 28 \\
\hline $1,500 \ldots$ & 1530. 12 & 33.43 & .30 & & & 1563.85 \\
\hline $1,750 \ldots$ & 2123. 25 & 95. 23 & 1. 75 & & & 2220.23 \\
\hline 2,000 & 2817. 34 & 211. 16 & 6. 54 & & & 3035.04 \\
\hline 2,500 & 4525. 96 & 662.84 & 42.32 & 0.0 & & 5231.12 \\
\hline $3,000 \ldots$ & $\begin{array}{r}6691.38 \\
{[.03]}\end{array}$ & $\begin{array}{r}1469.47 \\
{[.02]}\end{array}$ & $\begin{array}{r}150.44 \\
{[.01]}\end{array}$ & $\begin{array}{c}.1 \\
{[.1]}\end{array}$ & 0.0 & 8311.39 \\
\hline $4,000 \ldots$ & $\left.\begin{array}{c}12544.2 \\
{[4.0]}\end{array}\right]$ & $\begin{array}{r}4278.8 \\
{[2.1]}\end{array}$ & $\begin{array}{c}772.6 \\
{[1.1]}\end{array}$ & $\begin{array}{c}7.6 \\
{[5.6]}\end{array}$ & .2 & 17603.4 \\
\hline $5,000 \ldots$ & $\begin{array}{c}20662.3 \\
{[72.5]}\end{array}$ & $\begin{array}{c}8769.0 \\
{[37.4]}\end{array}$ & $\begin{array}{c}2174.1 \\
{[18.9]}\end{array}$ & $\begin{array}{r}83.3 \\
{[104.5]}\end{array}$ & 5.2 & 31693.9 \\
\hline
\end{tabular}

TABLE 4. Increments to functions for $\mathrm{O}_{2}{ }^{16}$ to obtain functions for the naturally occurring isotope mixture

\begin{tabular}{|c|c|c|c|c|}
\hline$T$ & $C_{p}^{\circ}$ & $\left(H^{\circ}-E_{0}^{\circ}\right)$ & \multicolumn{2}{|c|}{$-\left(F^{\circ}-E_{0}^{\circ}\right) / T$} \\
\hline${ }^{\circ} K$ & $\begin{array}{c}\text { cal deg-1 } \\
\text { mole }^{-1}\end{array}$ & cal mole $e^{-1}$ & $\begin{array}{c}\text { cal deg-1 } \\
\text { mole }\end{array}$ & $\begin{array}{c}\text { cal deg-1 } \\
\text { mole }^{-1}\end{array}$ \\
\hline 100 & 0. & 0.013 & 0.00770 & 0.00783 \\
\hline 200 & 0 & .013 & .00776 & .00782 \\
\hline 300 & 0.00005 & .015 & .00779 & .00784 \\
\hline 400 & .00011 & .023 & .00780 & .00786 \\
\hline 600 & .00017 & .053 & .00783 & .00792 \\
\hline 800 & .00016 & .09 & .00785 & .00796 \\
\hline 1,000 & .00013 & .12 & .00788 & .00800 \\
\hline 1,250 & .00010 & .14 & .00790 & .00801 \\
\hline 1,500 & .00007 & .16 & .00792 & .00802 \\
\hline 1,750 & .00006 & .18 & .00794 & .00804 \\
\hline 2,000 & .00005 & .20 & .00795 & .00805 \\
\hline 2,500 & .00003 & .22 & .00797 & .00806 \\
\hline 3,000 & .00002 & .23 & .00799 & .00807 \\
\hline 4,000 & .00002 & .25 & .00801 & .00807 \\
\hline 5,000 & .00001 & .26 & .00802 & .00807 \\
\hline
\end{tabular}

TABLE 5. Thermodynamic functions for the natural isotopic mixture of molecular oxygen in the standard ideal gas state at 20-degree intervals up to $700^{\circ} \mathrm{K}$

\begin{tabular}{|c|c|c|c|c|}
\hline$T$ & $\mathrm{C}_{p}^{\circ}$ & $H^{\circ}-E_{0}^{\circ}$ & $-\left(F^{\circ}-E_{0}^{\circ}\right) / T$ & $S^{\circ}$ \\
\hline${ }^{\circ} K$ & $\begin{array}{c}\text { cal deg-1 } \\
\text { mole }^{-1}\end{array}$ & cal mole-1 & $\begin{array}{c}\text { cal aeg-1 } \\
\text { mole }^{-1}\end{array}$ & $\begin{array}{c}\text { cal deg-1 } \\
\text { mole }^{-1}\end{array}$ \\
\hline 20 & 6.984 & 136. 39 & 23.373 & 30. 193 \\
\hline 40 & 6.964 & 275.81 & 28. 130 & 35.025 \\
\hline 60 & 6.960 & 415.03 & 30.930 & 37.848 \\
\hline 80 & 6.958 & 554.20 & 32.922 & 39.850 \\
\hline 100 & 6.958 & 693.36 & 34. 469 & 41. 402 \\
\hline 120 & 6.958 & 832.52 & 35. 733 & 42. 671 \\
\hline 140 & 6.958 & 971.67 & 36.803 & 43. 743 \\
\hline 160 & 6.958 & 1110.85 & 37. 730 & 44. 672 \\
\hline 180 & 6.959 & 1250.0 & 38.547 & 45. 492 \\
\hline 200 & 6. 961 & 1389.2 & 39. 279 & 46. 225 \\
\hline 220 & 6. 966 & 1528.5 & 39. 941 & 46. 889 \\
\hline 240 & 6.974 & 1667.9 & 40.546 & 47.495 \\
\hline 260 & 6.986 & 1807.4 & 41. 102 & 48.054 \\
\hline 280 & 7.002 & 1947.3 & 41. 618 & 48.572 \\
\hline 300 & 7.023 & 2087.6 & 42. 097 & 49.056 \\
\hline 320 & 7.050 & 2228.3 & 42.547 & 49.510 \\
\hline 340 & 7.080 & 2369.6 & 42.969 & 49. 938 \\
\hline 360 & 7.115 & 2511.5 & 43. 368 & 50.344 \\
\hline 380 & 7.154 & 2654.2 & 43. 745 & 50.730 \\
\hline 400 & 7.196 & 2797.7 & 44. 104 & 51.098 \\
\hline 420 & 7. 240 & 2942.1 & 44.445 & 51.450 \\
\hline 440 & 7. 286 & 3087.3 & 44. 771 & 51.788 \\
\hline 460 & 7. 334 & 3233.5 & 45. 083 & 52.113 \\
\hline 480 & 7.382 & 3380.7 & 45. 383 & 52.426 \\
\hline 560 & 7.431 & 3528.8 & 45.671 & 52.728 \\
\hline 520 & 7.480 & 3678.0 & 45. 948 & 53.021 \\
\hline 540 & 7.529 & 3828.0 & 46. 215 & 53.304 \\
\hline 560 & 7.577 & 3979.1 & 46. 473 & 53.579 \\
\hline 580 & 7.624 & 4131.1 & 46. 723 & 53.845 \\
\hline 600 & 7. 670 & 4284.1 & 46.964 & 54.105 \\
\hline 620 & 7.715 & 4437.9 & 47. 199 & 54.357 \\
\hline 640 & 7.759 & 4592.7 & 47. 426 & 54.602 \\
\hline 660 & 7.802 & 4748.3 & 47. 648 & 54.842 \\
\hline 680 & 7. 843 & 4904. 7 & 47. 863 & 55.075 \\
\hline 700 & 7.883 & 5062.0 & 48.072 & 55.303 \\
\hline
\end{tabular}

Calculated with $R=1.98714 \mathrm{cal} \mathrm{deg}^{-1} \mathrm{~mole}^{-1}$

Values of the thermodynamic functions were computed in the manner described for every 20 degrees up to $200^{\circ}$ and for temperatures $300^{\circ}, 400^{\circ}, 600^{\circ}, 800^{\circ}, 1,000^{\circ}, 1,250^{\circ}, 1,500^{\circ}$, $1,750^{\circ}, 2,000^{\circ}, 2,500^{\circ}, 3,000^{\circ}, 4,000^{\circ}$, and $5,000^{\circ}$ $\mathrm{K}$. Intermediate values were interpolated for $C_{p}^{\circ}$ at every 20 degrees up to $700^{\circ} \mathrm{K}$ and at every 100 degrees throughout the remainder of the temperature range covered. Using tabular integration, tables of $H^{\circ}-E_{0}^{\circ}, S^{\circ}$ and $-\left(F^{\circ}-E_{0}^{\circ}\right) / T$ were built up from the $C_{p}^{\circ}$ table. Good agreement was obtained with the directly computed values at all the above reference temperatures. The results are given at 20-degree intervals up to $700^{\circ} \mathrm{K}$ in table 5 and at 100-degree 
intervals up to $5,000^{\circ} \mathrm{K}$ in table 6 for the naturally occurring mixture of oxygen isotones.

TABLE 6. Thermodynamic functions for the natural isotopic mixture of molecular oxygen in the standard ideal gas state at 100-degree intervals up to $5,000^{\circ} \mathrm{K}$

\begin{tabular}{|c|c|c|c|c|}
\hline$T$ & $C_{p}^{\circ}$ & $H^{\circ}-E_{0}^{\circ}$ & $-\left(F^{\circ}-E_{0}^{\circ}\right) / T$ & $S^{\circ}$ \\
\hline${ }^{\circ} K$ & $\begin{array}{c}\text { cal deg } \text { dele }^{-1} \\
\text { mole }^{-1}\end{array}$ & cal mole ${ }^{-1}$ & $\begin{array}{c}\text { cal deg-1 } \\
\text { mole }^{-1}\end{array}$ & $\begin{array}{c}\text { cal deg-1 } \\
\text { mole }^{-1}\end{array}$ \\
\hline 100 & 6.958 & 693.36 & 34. 469 & 41. 402 \\
\hline 200 & 6. 961 & 1389. 2 & 39. 279 & 46. 225 \\
\hline 300 & 7. 023 & 2087.6 & 42.097 & 49. 056 \\
\hline 400 & 7. 196 & 2797. 7 & 44. 104 & 51.098 \\
\hline 500 & 7. 431 & 3528.8 & 45.671 & 52. 728 \\
\hline 600 & 7. 670 & 4284.1 & 46.964 & 54.105 \\
\hline 700 & 7. 883 & 5062.0 & 48.072 & 55. 303 \\
\hline 800 & 8.063 & 5859.6 & 49.044 & 56. 368 \\
\hline 900 & 8. 212 & 6673.7 & 49.912 & 57.327 \\
\hline 1,000 & 8. 336 & 7501.2 & 50.697 & 58. 199 \\
\hline 1,100 & 8. 439 & 8340.1 & 51. 416 & 58.998 \\
\hline 1,200 & 8.527 & 9188.6 & 52.079 & 59. 736 \\
\hline 1,300 & 8.604 & 10045.2 & 52.695 & 60.422 \\
\hline 1,400 & 8.674 & 10909. 2 & 53. 270 & 61.062 \\
\hline 1,500 & 8. 738 & 11779.8 & 53.810 & 61.663 \\
\hline 1,600 & 8.800 & 12656.8 & 54. 318 & 62. 229 \\
\hline 1,700 & 8.858 & 13539.7 & 54. 799 & 62.764 \\
\hline 1,800 & 8.916 & 14428.4 & 55. 256 & 63. 272 \\
\hline 1,900 & 8.973 & 15322.8 & 55.691 & 63.756 \\
\hline 2,000 & 9.029 & 16223 & 56.106 & 64. 217 \\
\hline 2,100 & 9.084 & 17129 & 56.503 & 64.659 \\
\hline 2,200 & 9.139 & 18040 & 56.883 & 65.083 \\
\hline 2,300 & 9.194 & 18956 & 57. 248 & 65.490 \\
\hline 2,400 & 9. 248 & 19879 & 57.600 & 65.883 \\
\hline 2,500 & 9. 301 & 20806 & 57.939 & 66.261 \\
\hline 2,600 & 9. 354 & 21739 & 58. 266 & 66.627 \\
\hline 2,700 & 9.405 & 22677 & 58. 582 & 66.981 \\
\hline 2,800 & 9.455 & 23620 & 58.889 & 67. 324 \\
\hline 2,900 & 9. 503 & 24568 & 59.185 & 67.657 \\
\hline 3,000 & 9.551 & 25520 & 59.473 & 67.980 \\
\hline 3,100 & 9. 596 & 26478 & 59. 753 & 68. 294 \\
\hline 3,200 & 9.640 & 27440 & 60.024 & 68.599 \\
\hline 3,300 & 9. 682 & 28406 & 60. 289 & 68.896 \\
\hline 3,400 & 9. 723 & 29376 & 60.546 & 69. 186 \\
\hline 3,500 & 9. 762 & 30350 & 60.797 & 69.468 \\
\hline 3,600 & 9. 799 & 31328 & 61.042 & 69. 744 \\
\hline 3,700 & 9.835 & 32310 & 61.280 & 70.013 \\
\hline 3,800 & 9.869 & 33295 & 61.514 & 70.276 \\
\hline 3,900 & 9.901 & 34284 & 61. 742 & 70.532 \\
\hline 4,000 & 9.932 & 35275 & 61.965 & 70.783 \\
\hline
\end{tabular}

TABLE 6. Thermodynamic functions for the natural isotopic mixture of molecular oxygen in the standard ideal gas state at 100-degree intervals up to $5,000^{\circ} \mathrm{K}$-Continued

\begin{tabular}{|c|c|c|c|c|}
\hline$T$ & $C_{p}^{\circ}$ & $H^{\circ}-E_{0}^{\circ}$ & $-\left(F^{\circ}-E_{0}^{\circ}\right) / T$ & $S^{\circ}$ \\
\hline${ }^{\circ} K$ & $\begin{array}{c}\text { cal deg-1 } \\
\text { mole }^{-1}\end{array}$ & cal mole-1 & $\begin{array}{l}\text { cal deg-1 } \\
\text { mole } e^{-1}\end{array}$ & $\begin{array}{c}\text { cal deg-1 } \\
\text { mole } e^{-1}\end{array}$ \\
\hline 4,100 & 9. 961 & 36270 & 62.183 & 71.029 \\
\hline 4,200 & 9. 988 & 37267 & 62.396 & 71. 269 \\
\hline 4,300 & 10. 015 & 38267 & 62.605 & 71.505 \\
\hline 4,400 & 10. 039 & 39270 & 62.810 & 71.735 \\
\hline 4,500 & 10.062 & 40275 & 63.011 & 71.961 \\
\hline 4,600 & 10. 084 & 41282 & 63.208 & 72.182 \\
\hline 4,700 & 10. 104 & 42292 & 63.401 & 72.399 \\
\hline 4,800 & 10. 123 & 43303 & 63.591 & 72.613 \\
\hline 4,900 & 10. 140 & 44316 & 63.777 & 72.821 \\
\hline 5,000 & 10,156 & 45331 & 63.960 & 73. 026 \\
\hline
\end{tabular}

(Calculated with $R=1.98714 \mathrm{cal} \mathrm{deg}^{-1} \mathrm{~mole}^{-1}$

\section{References}

[1] H. L. Johnston and M. K. Walker, J. Am. Chem. Soc. 55, 172 (1933).

[2] H. L. Johnston and M. K. Walker, J. Am. Chem. Soc. 5\%, 682 (1935).

[3] J. Curry and G. Herzberg, Ann. Physik 19, 800 (1934).

[4] R. Schlapp, Pbys. Rev. 51, 342 (1937).

[5] L. Herzberg and G. Herzberg, Astrophys. J. 105, 353 (1947).

[6] H. Sponer, Molecular spectra and their application to chemical problems. I. Tables. (Julius Springer, Berlin, 1935).

[7] G. Herzberg, Naturwissenschaften 20, 577 (1932).

[8] P. Swings, Astrophys. J. 97, 72 (1943).

[9] J. L. Dunham, Phys. Rev. 41, 721 (1932).

[10] H. A. Kramers, Z. Physik 53, 422 (1929).

111] H. W. Woolley, J. Chem. Phys. 9, 470 (1941).

[12] R. T. Birge, Rev. Modern Phys. 13, 233 (1941).

[13] A. R. Gordon and C. Barnes, J. Chem. Phys. 1, 297 (1933).

Washington, October 15, 1947. 